\title{
AN INTERPRETATION OF GRAVITY ANOMALIES OVER THE ANDIGAMA AND TABBOWA SEDIMENTARY BASINS IN NORTH-WEST OF SRI LANKA
}

\author{
D. A. TANTRIGODA AND P. GEEKIYANAGE \\ Department of Physics, University of Sri Jayewardenepura, Nugegoda, Sri Lanka.
}

(Date of receipt : 28 November 1990)

(Date of acceptance : 20 March 1991)

\begin{abstract}
The sub-surface structure of the Andigama and Tabbowa sedimentary basins filled with Upper Jurassic (Gondwana) sediments in NW of Sri Lanka has been investigated interpreting isostatic gravity anomalies. A detailed three-dimensional model for the Andigama basin has been produced using the end correction method. The total volume of the Gondwana sediments present in the basin is found to be $65 \mathrm{~km}^{3}$ and the maximum depth to the basement is 1.2 $\mathrm{km}$. A contour map of the sub-surface of the basin is also presented. The limited amount of gravity data available over the Tabbowa basin has been used to obtain a two-dimensional model. According to the model, this sedimentary basin takes an approximate shape of a triangular wedge and maximum depth to the basement is $1.5 \mathrm{~km}$.
\end{abstract}

\section{Introduction}

A very large extent of Sri Lanka is underlain by crystalline non-fossiliferous metamorphic rocks belonging to Precambrian age. These rocks have been classified into two units known as the Highland Series and the Vijayan Complex. The rest of the island is mainly covered by sedimentary rocks of various ages. Sedimentary rocks of Upper Jurassic age can be found in down faulted basins situated at Andigama and Tabbowa in NW of Sri Lanka (Figure 1). Although surface geology of Andigama and Tabbowa is well studied, ${ }^{1}$ very little is known about their sub-surface structures. An attempt has been made here to unravel the deep structure of two basins interpreting gravity anomalies. Isostatic anomaly maps (Figure 2 and Figure 3 ) over the basins prepared by Hatherton et al. ${ }^{2}$ were used for this purpose. A three-dimensional model is presented for the sub-surface of the Andigama basin using the end correction method. ${ }^{3,4,5} \mathrm{~A}$ twodimensional model is presented for the Tabbowa basin. This is because of the unavailability of sufficient gravity data over the Tabbowa basin which is partly covered with a large tank.

\section{Previous Geophysical Studies of North and North-West of Sri Lanka}

As mentioned in the introduction, collection of gravity data over the Andigama and Tabbowa basins has been carried out by Hatherton et al. ${ }^{2}$ Further, they have interpreted an $\mathrm{E}-\mathrm{W}$ profile of the isostatic anomaly map of Andigama (profile 


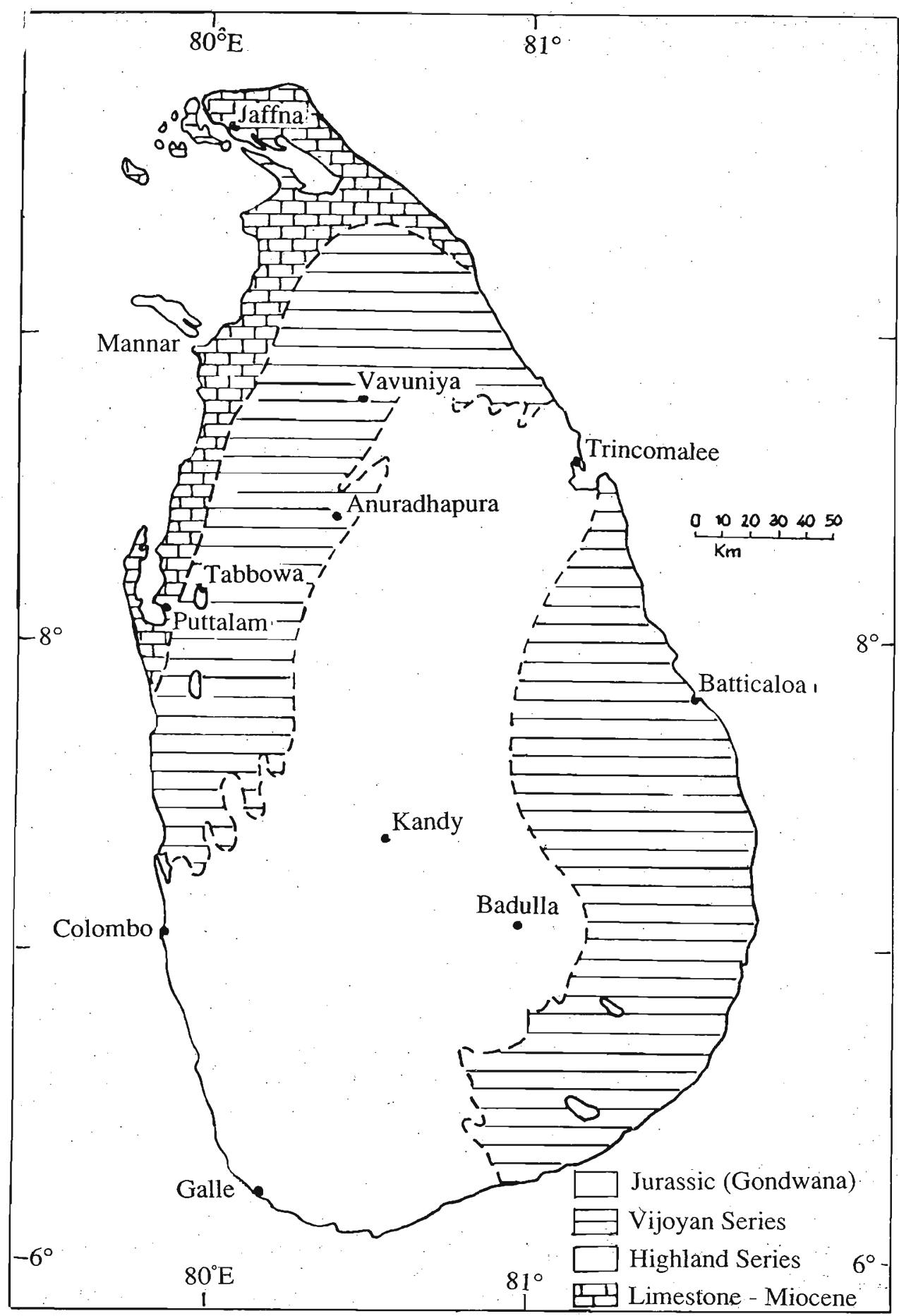

Figure 1: Sketch map of Geology of Sri Lanka. 


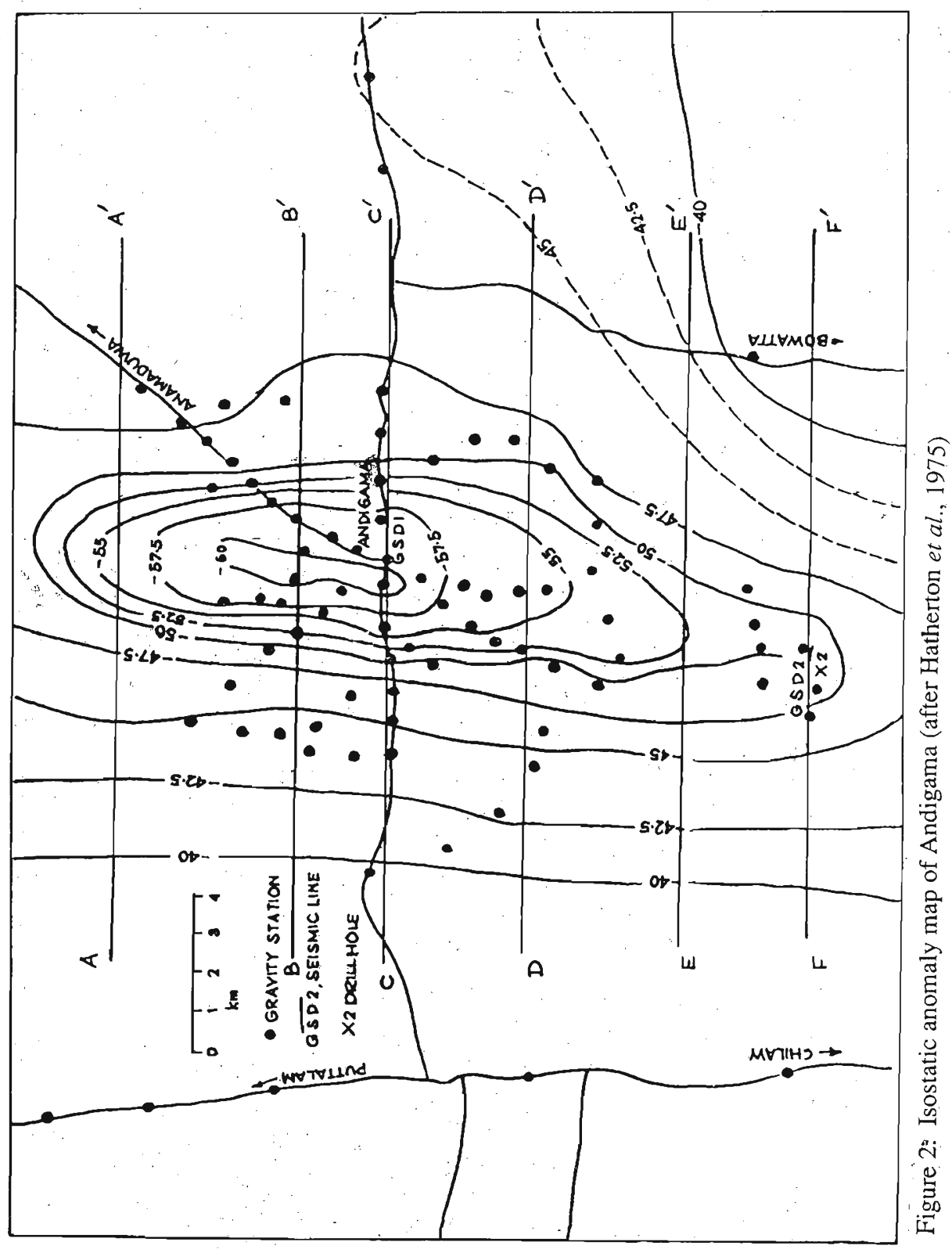




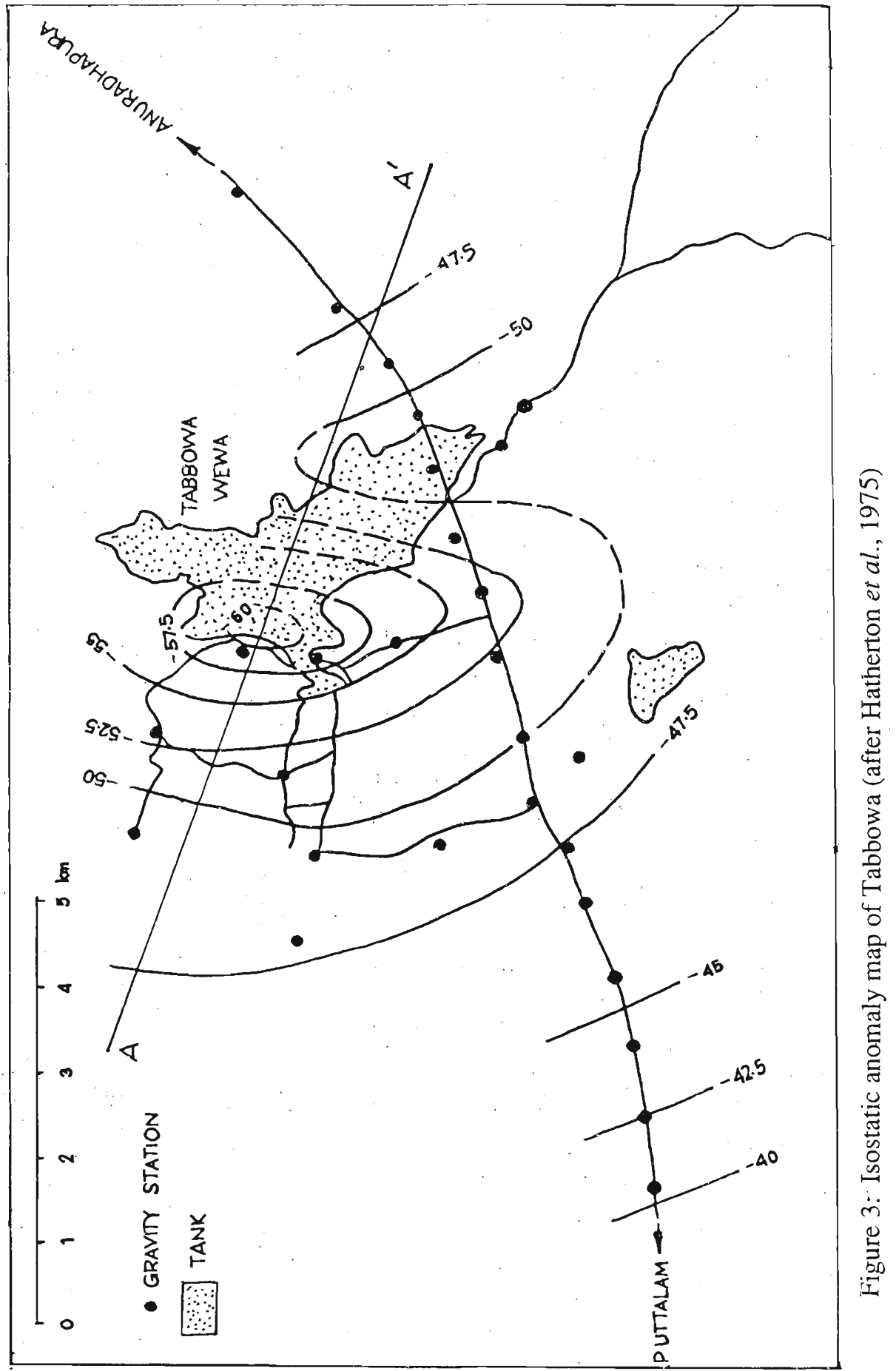


$\mathrm{CC}^{\prime}$ of Figure 2) in terms of a sedimentary basin filled with Jurassic deposits and produced two different two-dimensional models (Figure 4). In the first model, which has a density contrast of $-300 \mathrm{~kg} / \mathrm{m}^{3}$, thickness of the sediments is $1.2 \mathrm{~km}$ in the western side and $0.9 \mathrm{~km}$ in the eastern side. In the second model, thickness of the sediments in the western and eastern sides of the basin are $0.9 \mathrm{~km}$ and $0.65 \mathrm{~km}$ respectively while its density contrast is $-400 \mathrm{~kg} / \mathrm{m}^{3}$.

Two seismic lines named "G.S.D.1." and "G.S.D.2" (Figure 2) have been shot over Andigama region by "La Compagine Generale de Geophysique" for the Petroleum Corporaton of Sri Lanka in 1968. The "G.S.D.1" seismic line was shot almost over Andigama, which is very close to the profile CC' (Figure 2) while the "G.S.D.2" seismic line was shot at Pallama just south of Andigama. According to the results of the "G.S.D.1" thickness of the sediments in the eastern side of the basin is much lower than that of western side as predicted by the gravity models. Analysis of the seismic line "G.S.D.2" shows that the thickness of sediments is very low in southern side of the basin near Pallama.

\section{Interpretation of Gravity Anomalies over Andigama Region}

Normal two-dimensionai methods are not adequate for interpretation of gravity anomalies over Andigama region. However, detailed three-dimensional interpretation is not suitable as it involves lengthy calculations leading to a large amount of computing time. The interpretation was therefore carried out using the automatic end correction method which is an approximation to the complete three-dimensional modelling.

The basement of the Andigama basin consists of Vijayan rocks. According to Hatherton et al. ${ }^{2}$ density of Vijayan rocks varies from $2600 \mathrm{~kg} / \mathrm{m}^{3}$ to 3130 $\mathrm{kg} / \mathrm{m}^{3}$. Density measurements carried out by Technoexport of U.S.S.R. ${ }^{7}$ at a site close to Andigama revealed a density of $2670 \mathrm{~kg} / \mathrm{m}^{3}$ for the Vijayan rocks and this value was used in the interpretation. Andigama sedimentary basin is filled with Gondwana sediments and density of Gondwana sediments ${ }^{2}$ in Sri Lanka is $2400 \mathrm{~kg} / \mathrm{m}^{3}$.

Six E-W profiles AA', BB', CC', DD', EE' and FF' of detailed isostatic anomaly map of Andigama region (Figure 2) were interpreted as a sedimentary basin filled with Jurassic (Gondwana) deposits. All these interpietations have been carried out after separation of a regional level from the isostatic anomaly map.

The profile CC' passes almost through the centre of the anomaly and the results of its interpretation is discussed below (Figure 5). Thickness of the Gondwana sediments below the profile CC' varies from $0.90 \mathrm{~km}$ in the eastern side to $1.20 \mathrm{~km}$ in the western side. Further, Figure 5 shows that the boundary between the Vijayan rocks and the Gondwana sediments is very steep at the western side and relatively less steep at the eastern side. The application of end correction method requires the division of the trial model into a number of horizontal prisms perpendicular to the profile and the way in which this 


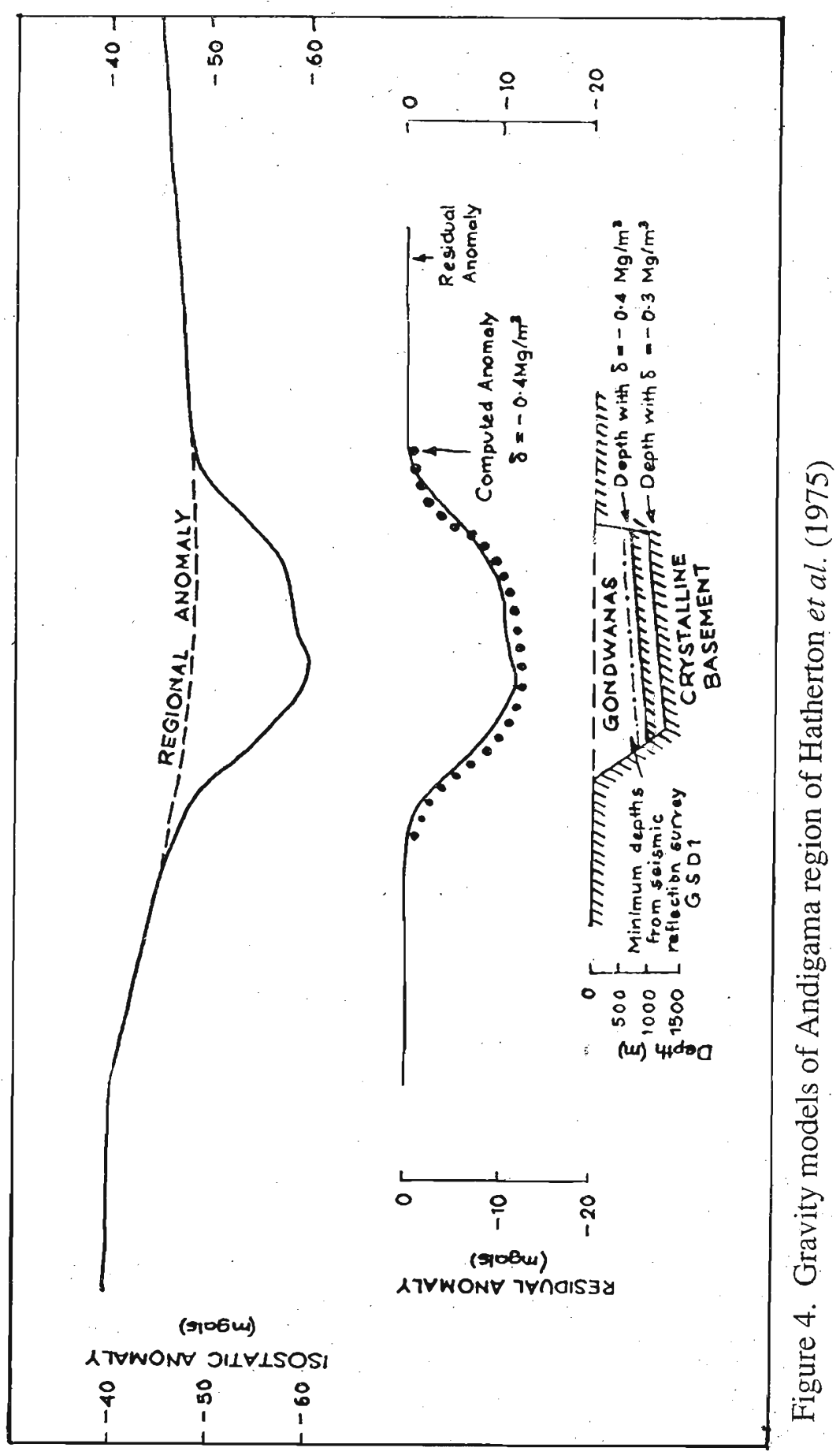


division was carried out is shown in Figure 6. This figure also gives the partial strike lengths of the model along the northern side and along the southern side. Results of the interpretations of profiles AA', BB', CC', DD', EE' and FF' which were carried out using the end correction method, are depicted in Figure 7. A contour map of the sedimentary basin was constructed using results of the interpretations of six parallel profiles and is shown in Figure 8. The approximate volume of Gondwana sediments present in the basin calculated using this map is $65 \mathrm{~km}^{3}$.

\section{Interpretation of Gravity Anomalies over Tabbowa Region}

As mentioned earlier, another sedimentary basin filled with Jurassic deposits is found within Vijayan rocks at Tabbowa. It is believed that this basin also belongs to the Gondwana series. ${ }^{1}$ A substantial portion of the basin is occupied by the Tabbowa tank and as a result, gravity measurements have not been carried out over this part of the basin. The available gravity data (Figure 3 ) is not sufficient to perform a detailed three-dimensional interpretation and therefore a two-dimensional interpretation was carried out. Figure 9 shows the results of a two-dimensional interpretation of the profile AA' of the isostatic anomaly map of the Tabbowa region (Figure 3). Thickness of the sediments in the basin is ranging from $1.5 \mathrm{~km}$ at the western side to $1.2 \mathrm{~km}$ at the eastern side and the width of the basin along the profile is $2.7 \mathrm{~km}$. Figure 3 further shows that the boundary between the Vijayan rocks and the Gondwana sediments is very steep at the eastern side compared to that at the western side. The densities used for the Vijayan rocks and Gondwana sediments are $2670 \mathrm{~kg} / \mathrm{m}^{3}$ and $2400 \mathrm{~kg} / \mathrm{m}^{3}$ respectively as in the previous interpretation.

\section{Discussion}

Hatherton et al. ${ }^{2}$ interpreted the isostatic anomaly over Andigama region and produced two 2-D models for the sub-surface structure. An attempt has been made here to produce a more complete three-dimensional model using the end correction method which is an improvement to the previous two-dimensional models.

The seismic line "G.S.D.1", which was shot almost over the centre of the anomaly revealed that the thickness of the Gondwana sediments is varing from $1.2 \mathrm{~km}$ at the western side to $0.9 \mathrm{~km}$ at the eastern side of the basin. Interpretation of profile CC' which is lying almost over the centre of the anomaly also leads to similar results. Further, five more parallel E-W profiles were also interpreted using the end correction method. A contour map of the Gondwana sedimentary basin was then constructed using the results of six parallel profiles and the approximate volume calculated for the Gondwana sediments in the basin is $65 \mathrm{~km}^{3}$.

A two-dimensional gravity model for the Tabbowa region was obtained by interpreting an $\mathrm{E}-\mathrm{W}$ profile of the isostatic anomaly map. The cross section of 


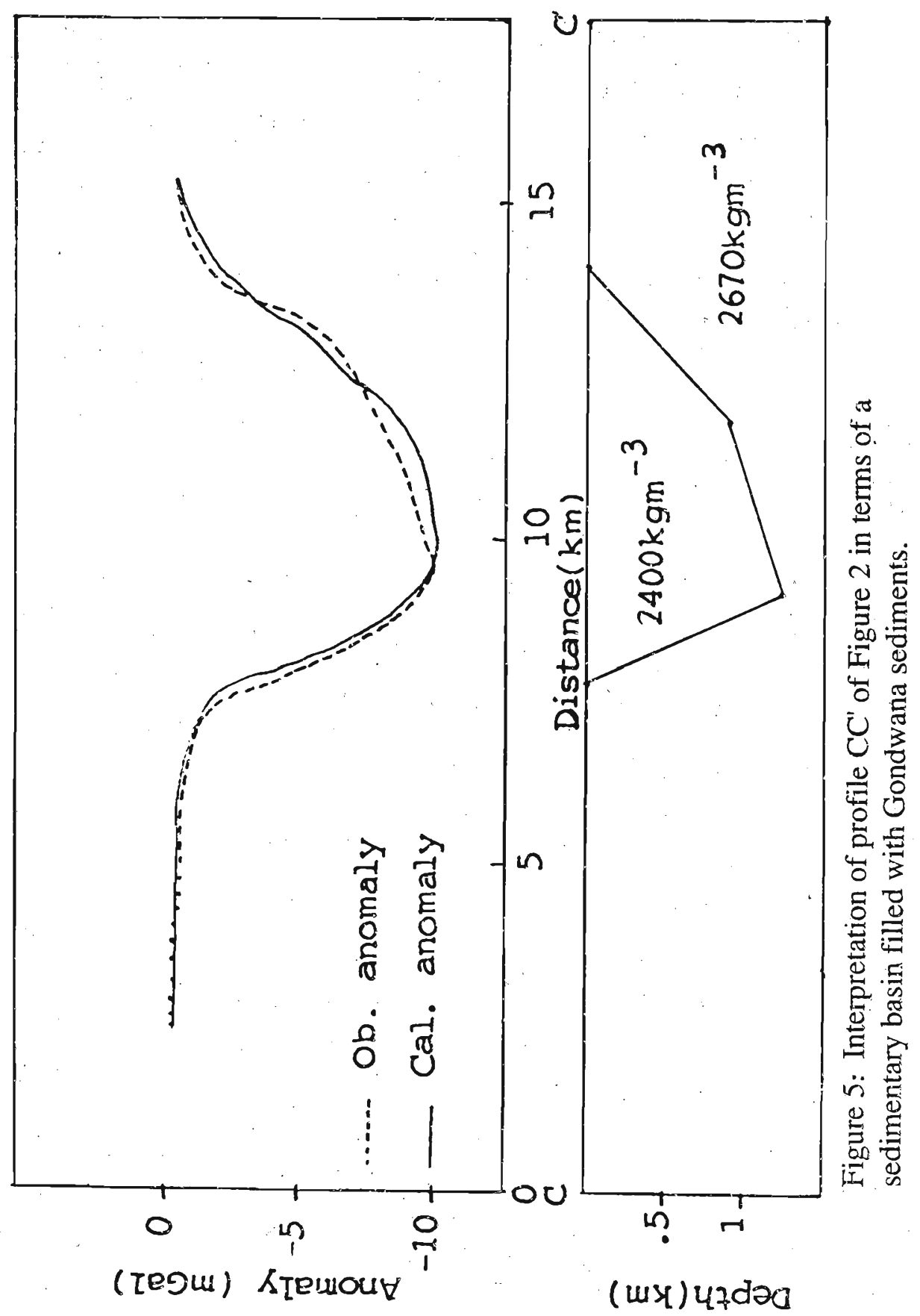




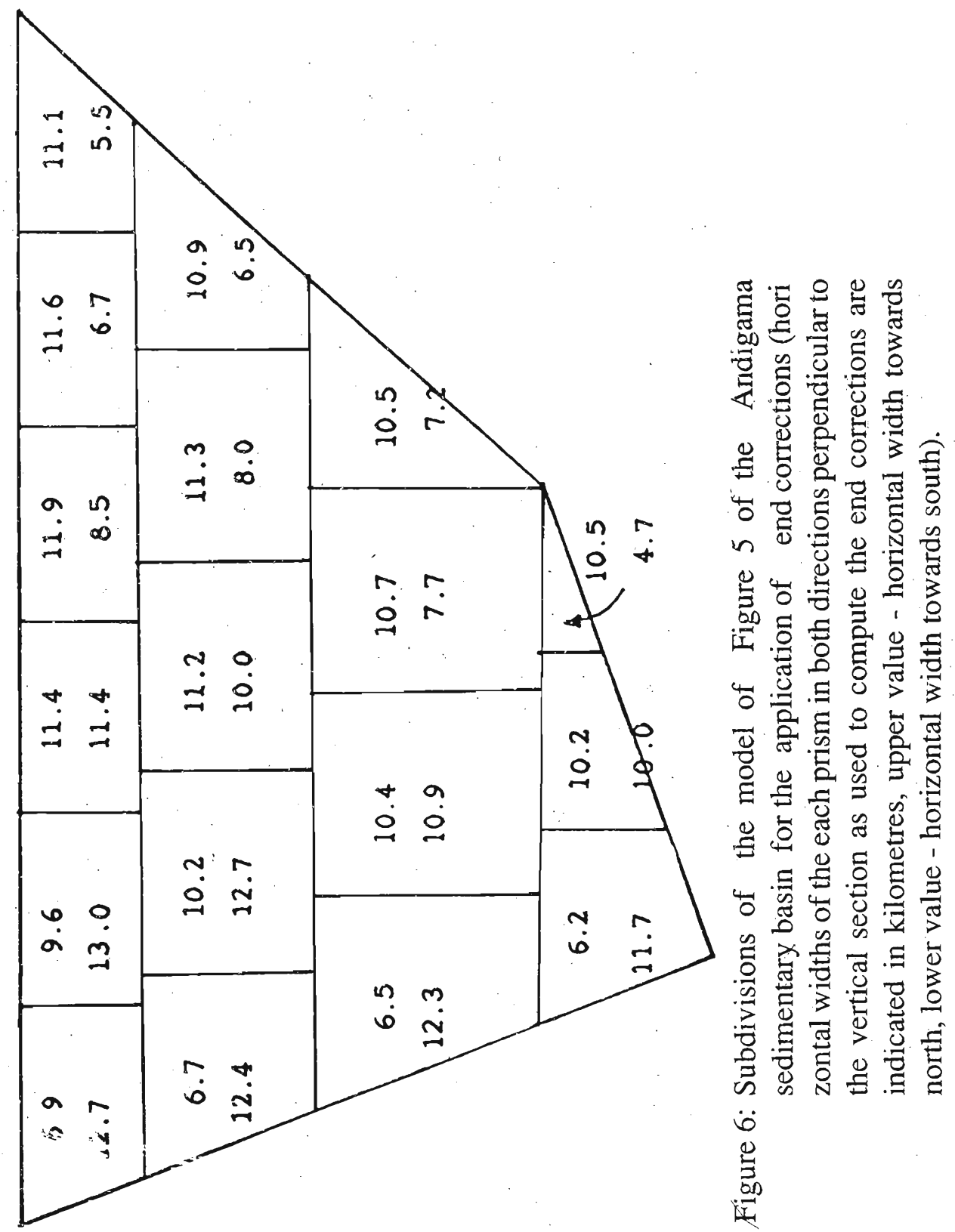



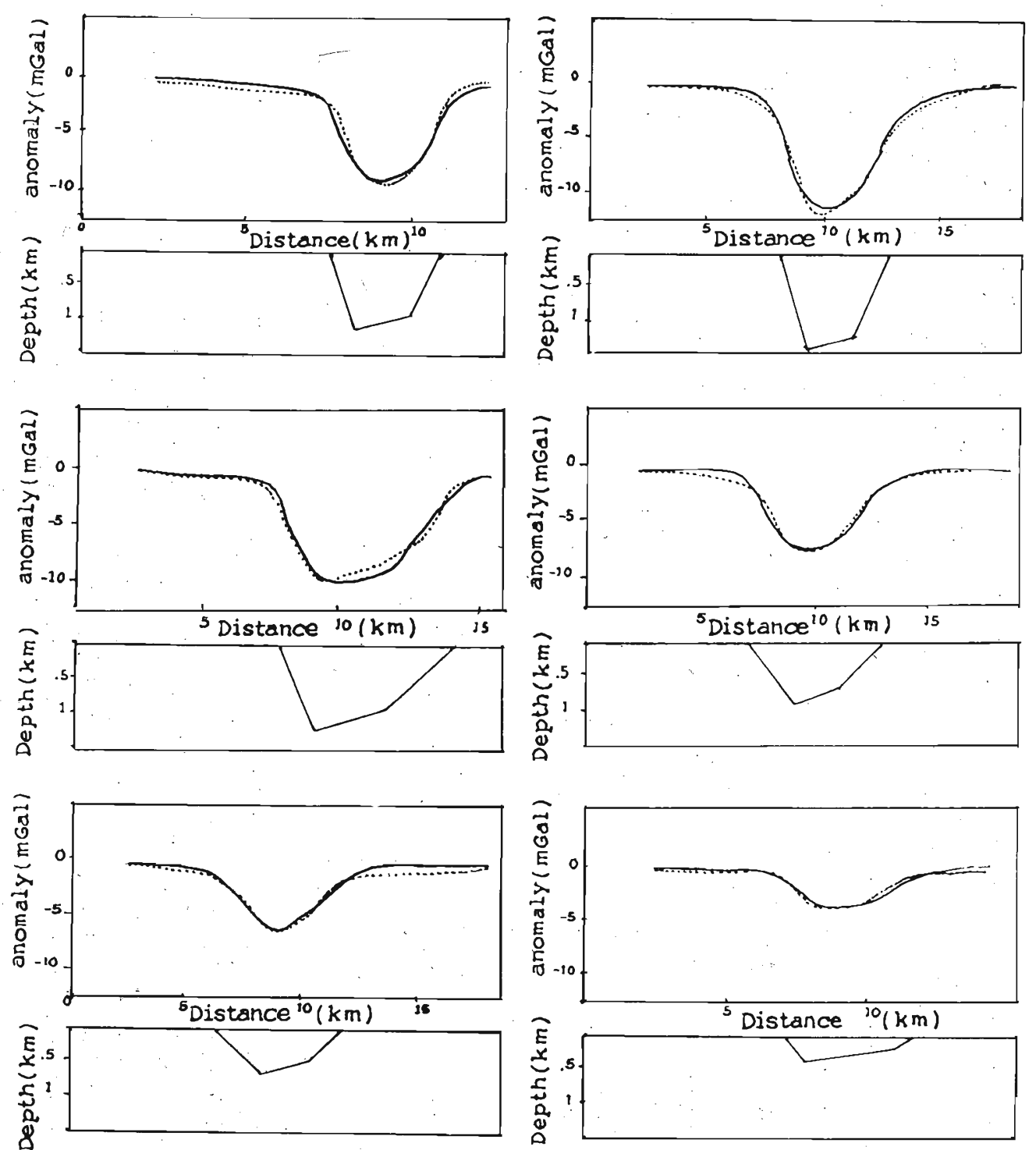

Ob. anomaly

Cal. anomaly

Figure 7: Interpretation of profiles $\mathrm{AA}^{\prime}, \mathrm{BB}^{\prime}, \mathrm{CC}^{\prime}, \mathrm{DD}^{\prime}, \mathrm{EE}^{\prime}$ and

.FF' of Figure 3 in terms of a sedimentary basin filled with Gondwana sediments. 


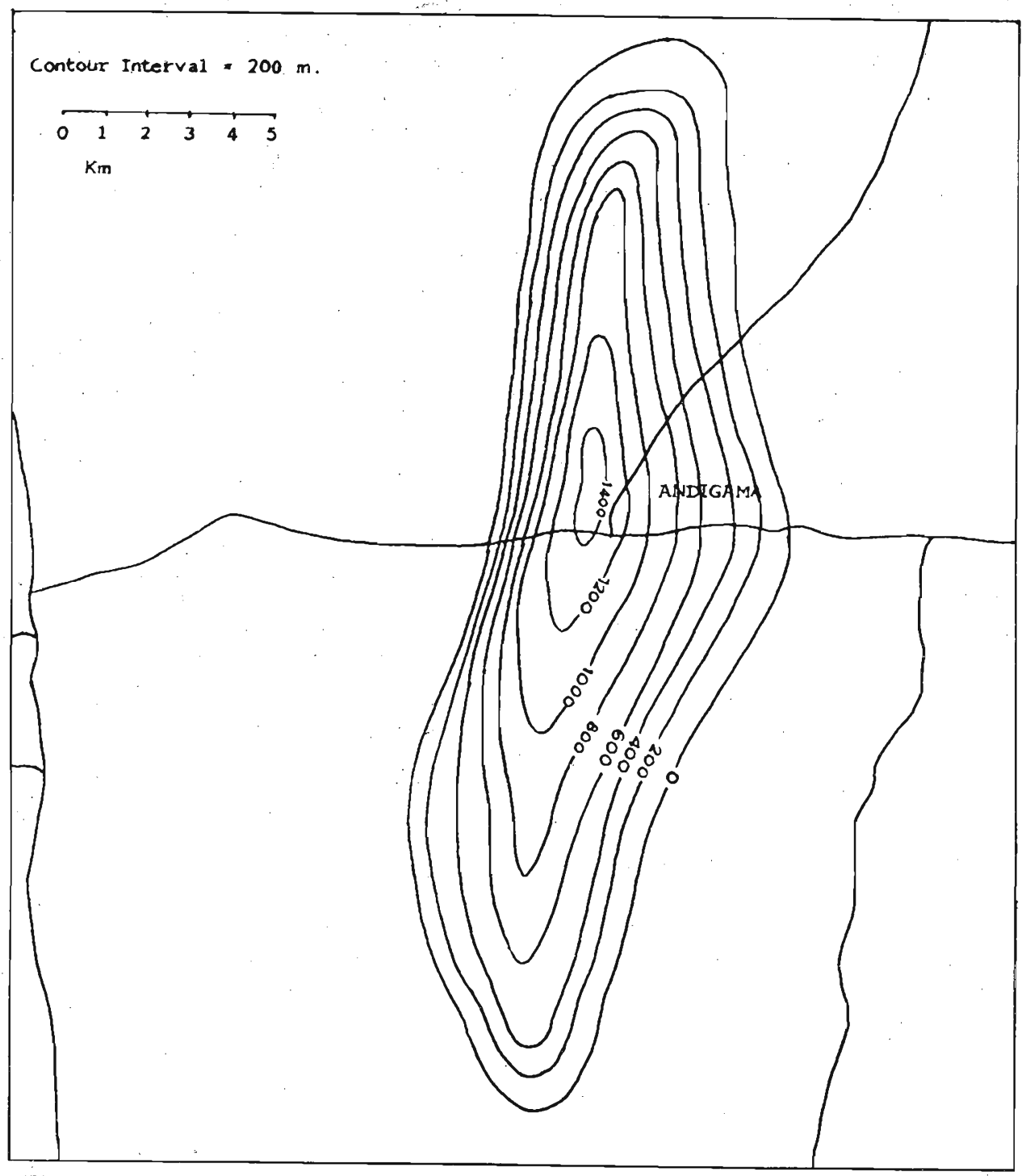

Figure 8: Contour map of the Andigama sedimentary basin based on the gravity interpretation. 

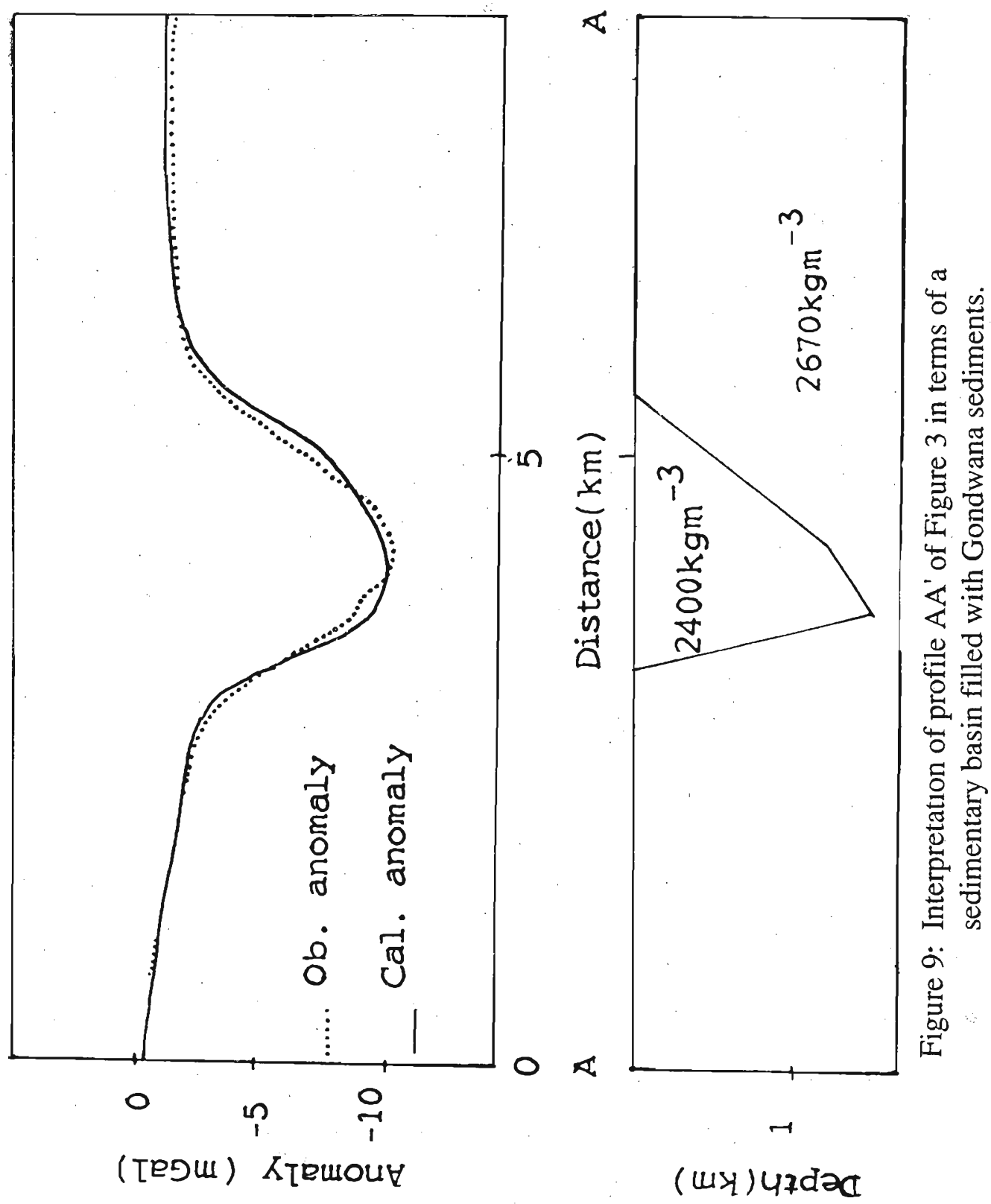
this model takes an approximate shape of a triangle and maximum depth to the basement is $1.5 \mathrm{~km}$. Further, this model has a steep boundary contact at the western side, compared to that of the eastern side. A more complete threedimensional model for the sub-surface of Tabbowa region could have been produced using the end correction method, provided more gravity observations were available.

The Bouguer anomaly map of the island ${ }^{2}$ shows another prominent gravity low over the Jaffna peninsula in northern Sri Lanka. Tantrigoda and Geekiyanage ${ }^{6}$ interpreted this anomaly in terms of a sedimentary basin filled with outcropping Miocene limestones and underlying Gondwana sediments. It is of interest to note that Tabbowa, Andigama and Jaffna basins and also similar Gondwana basins in Madras in east coast of peninsula India lie almost in a straight line.

\section{Acknowledgements}

Financial assistance, for this study was provided by the National Resources, Energy and Science Authority of Sri Lanka (Grant No. RG/86/P/03) and this is gratefully acknowledged. We wish to thank Prof. P. C. B. Fernando for his encouragement and advice. We would also like to thank Messrs D. E. de S. Jayewardene, Ranjith Fernando, D. A. Kathriarachchi, U. Udakandage and A. Mudunkotuwa for helping in numerous ways. We are grateful to Mr. Daham Wimalasena, former Chairman, Petroleum Corporation of Sri Lanka, for allowing us to use Geophysical data available at the Corporation. The gravity data used in this study was obtained from the Geological Survey Department of Sri Lanka. Illustrations were drafted by Mr. G. f. De Alwis and the manuscript was typed by Miss. K. A. A. P. Ratnayake.

\section{References}

1. COORAY, P. G. (1988) An Introduction to the Geology of Ceylon. Colombo: National Museums Department.

2. HATHERTON, T., PATTIARACHCHI, D. B. \& RANASINGHE, V. V. C. (1975) Gravity map of Sri Lanka. 1:1,000,000, Professional Paper 3, Colombo: Sri Lanka Geological Survey Department.

3. NETTLETON, L. L. (1940) Geophysical prospecting for Oil. McGraw - Hill New York and London.

4. RASMUSSEN, R. \& PEDERSEN, L. B. (1979) End corrections in potential field modelling. Geophysical prospecting. 27:

5. TANTRIGODA, D.A. (1990) An automatic method for sub-dividing a three dimensional body useful in gravity and magnetic modelling. Bollettino Di Geofisica Teorica Ed Applicata (in press).

6. TANTRIGODA, D. A. and GEEKIYANAGE, P. (1988) An interpretation of gravity anomalies over the Jaffna peninsula in Northern Sri Lanka. Journal of Geological Society of Sri Lanka. 1: 30-34.

7. TECHNOEXPORT OF USSR. (1976) Results of overall processing of core material Mesozoic and Cenozoic deposits met by bore hole No. 1, Mannar, Sri Lanka: Petroleum Corporation of Sri Lanka. 